Health thinking' and approaches that may be (and have been) successfully introduced into the national health policies and programs, in the case of some local and regional ongoing experiences in Brazil, include the following:

i. development or strengthening of a clear understanding that almost all young or adult 'citizens' and/or 'patients' are also 'workers';

ii. introduction of the classic Ramazzinian question ('what is your occupation?'), improved by Sir Percival Pott, by adding a temporal dimension (occupational anamnesis), as a routine, into the Family/Primary health practice;

iii. mapping, visiting productive premises or other economic activities located within the territorial jurisdiction of the Primary/Family health responsibility;

iv. analysis of all economic/productive informal activities carried out within houses, involving children, minors and women, among other activities. There are successful outcomes that may be shared.

\section{0d NEW METHODS IN EPIDEMIOLOGY OF WORK-RELATED ASTHMA}

O Dumas. INSERM, U1168, VIMA: Ageing and chronic diseases. Epidemiological and public health approaches and Univ Versailles Saint-Quentin-en-Yvelines, Villejuif, France

\subsection{6/oemed-2018-ICOHabstracts.369}

Around $15 \%$ of adult asthma may be attributable to occupational exposures. Among adults with asthma, occupational exposures have also been associated with disease exacerbations and poor asthma control. While the number of identified occupational asthmagens (hazards known to induce asthma) increases regularly, the burden of work-related asthma remains underestimated. Moreover, for some categories of exposure such as cleaning products, specific causal agents remain unclear, limiting the development of prevention strategies. Two of the main methodological challenges in epidemiological studies on work-related asthma are (1) exposure assessment, as a differential misclassification bias may be particularly important when exposure is self-reported; and (2) the healthy worker effect, as individual with asthma may change job shortly after experiencing work-related symptoms. New methodological approaches have been developed to address these two challenges and will be presented. Methods for evaluation of exposure to specific cleaning products and disinfectants will be discussed, illustrating the interest of using (a) job-task-exposure matrices instead of common job-exposure matrices or self-report to reduce exposure misclassification; and (b) a smartphone application with a barcode reader to evaluate exposure to numerous chemicals contained in cleaning products/disinfectants. To address the healthy worker effect, new approaches based on causal inference methods have been developed in occupational epidemiology. The specific impact of the healthy worker effect in work-related asthma studies, and how it can be addressed using marginal structural models, will be presented. In summary, new epidemiological methods may help better evaluating the burden of work-related asthma, and improve ability to identify specific harmful agents, which is warranted to suggest new targets for work-related asthma prevention.

\section{0e BIAS AND TARGET PARAMETERS IN OCCUPATIONAL EPIDEMIOLOGY}

AMNeophytou. Division of Environmental Health Sciences, School of Public Health, University of California, Berkeley, Berkeley, California, USA

\subsection{6/oemed-2018-ICOHabstracts.370}

Along with the issues and limitations inherent in all observational studies, occupational epidemiologic studies have to address biases arising from the healthy worker effect. This mechanism can be described as one of a time varying confounder affected by prior exposure, which cannot be addressed in standard regression approaches. Recent applications of a series of methods collectively known as 'g-methods', have sought to address this issue in occupational epidemiologic studies. Furthermore, some studies seek to provide direct estimates of risk (cumulative incidence) in relation to exposures of interest, under hypothetical exposure scenarios and interventions. These measures are advantageous compared to traditional measures of contrast relying on the hazard or the odds, and are of direct significance to risk and policy assessment. This talk will portray issues that may give rise to bias in occupational studies, such as time-varying confounding affected by prior exposure, right censoring, competing events, and left truncation in relation to methods used to address them. We also lay out steps in identifying target quantities of interest, given the existing knowledge and questions at hand, assessing whether that quantity is identifiable with available estimation methods, and the interpretation of these quantities after estimation.

\section{STIGMA TOWARDS WORKERS DIAGNOSED WITH OCCUPATIONAL DISEASES}

${ }^{1}$ Ayş̧e Coşkun Beyan, ${ }^{2}$ Serhat Erdal, 'Nur Şafak Alıcı, ${ }^{1}$ Arif Çımrın, ${ }^{1}$ Yücel Demiral. 'Dokuz Eylul University Occupational Medicine Department, Izmir, Turkey; ${ }^{2}$ Dokuz Eylul University Public Health Department, Izmir, Turkey

\subsection{6/oemed-2018-ICOHabstracts.371}

Introduction Stigma has been defined as 'the situation of the individual who is disqualified from full social acceptance or social 'disgrace' arising within social relations' or biassed acts or behaviours. Stigma related to chronic health conditions have been known for a long time. Especially, internal and external (perceived and experienced) stigmatisation have been described among the patients with communicable diseases. Despite a growing awareness of chronic diseases, there is not yet enough research about patients with occupational diseases (OD) with regards to stigmatisation. This research aimed to investigate the scope and types of stigmatisation among OD patients in an outpatients clinic.

Methods This is a qualitative research. Semi-structured indepth interviews conducted by two interviewers. 13 patients who diagnosed OD between November 2013-February 2016 recruited to the study. The interviews conducted with taperecorded accompanied by note-taking. The tape records resolved and evaluated by content analysis methods.

Result In our study, we found that at least one theme of internal or external stigmatisation was found in all employees after OD diagnosis. In particular, employees who are symptomatic have been shown to be embarrassed by the complaints and 
distracted from their social environment due to their illness, and their illnesses are considered as communicable diseases. It was seen that patients were tended to hide their diseases because of the fear of job loss and thinking they were being exposed to discrimination in the workplace.

Discussion After OD diagnosis, external stigmatisation is an important and prominent issue. Ensuring job security of the workers with OD and keeping them in working life (return to work and rehabilitation) should be prioritised to prevent stigmatisation. There is a need for investigations to explore the prevalence and causes of the stigmatisation in the workplaces due to chronic diseases including occupational diseases.

\section{BASIC TYPOLOGY OF SENTINEL AND ALERT APPROACHES TO IDENTIFY NEW AND EMERGING WORK-RELATED DISEASES}

\begin{abstract}
${ }^{1}$ Jelena Bakusic*, ${ }^{2}$ Annet Lenderink, 1,3 Sofie Vandenbroeck, ${ }^{1,3}$ Charlotte Lambreghts, ${ }^{4}$ Jos Verbeek, ${ }^{5}$ Stefania Curti, ${ }^{5}$ Stefano Mattioli, ${ }^{1,3}$ Lode Godderis. ${ }^{1}$ Environment and Health, KU Leuven, Belgium; ${ }^{2}$ Coronel Institute of Occupational Health, AMC/University of Amsterdam, The Netherlands; ${ }^{3}$ IDEWE, External Service for Prevention and Protection at Work, Heverlee, Belgium; ${ }^{4}$ Cochrane Work Review Group, Finnish Institute of Occupational Health, Kuopio, Finland; ${ }^{5}$ Department of Medical and Surgical Sciences, University of Bologna, Bologna, Italy
\end{abstract}

\subsection{6/oemed-2018-ICOHabstracts.372}

Objective Changes in working conditions give rise to new occupational health risks and work-related diseases (WRDs). Monitoring these new WRDs is essential for their early recognition and prevention and requires a comprehensive approach, using several complementary methods. The aim of this review is to provide an overview and basic typology of different approaches to detect new/emerging WRDs.

Methods We conducted an extensive scientific literature search combining terms for the following three concepts:

- surveillance/reporting systems;

- occupational/work-related diseases; and

- new or emerging risks.

In addition, a grey literature search was performed of both grey literature databases and relevant EU and research institute websites for additional resources.

Results We identified a total of 75 surveillance systems from 26 different countries. We set up a basic typology of these systems dividing them into four main groups. Compensationbased systems $(n=22)$ were designed to gather data for compensation purposes and are insurance-driven. Non-compensation-related systems $(n=34)$ were created with the aim of improving the collection and analysis of data to measure trends in occupational and work-related diseases. Sentinel systems $(n=12)$ were specifically designed to provide a warning signal that will initiate health interventions and preventive actions. Finally, public health surveillance systems $(n=7)$ aim to monitor the health of the general population, but can also be used for work-related surveillance. These four main types further differed in terms of disease coverage, means of data collection, evaluation of work-relatedness, follow-up of new/ emerging risks, link with prevention etc.

Conclusion Sentinel systems seem to have the most suitable approach to detect and alert to new/emerging WRDs. Nevertheless, systems identified in the other three groups can also contribute to identifying new/emerging WRDs, despite being primarily designed for other purposes.

\section{ESTIMATION OF THE GLOBAL BURDEN OF MESOTHELIOMA DEATHS FROM INCOMPLETE NATIONAL MORTALITY DATA}

${ }^{1}$ Odgerel Chimed-Ochir*, ${ }^{2}$ Ken Takahashi, ${ }^{3}$ Tom Sorahan, ${ }^{4}$ Tim Driscoll, ${ }^{5}$ Christina Fitzmaurice, ${ }^{1}$ Makoto Yoko-o, ${ }^{6}$ Kittisak Sawanyawisuth, ${ }^{7}$ Sugio Furuya, ${ }^{8}$ Fumihiro Tanaka, ${ }^{9}$ Seichi Horie, ${ }^{2}$ Nico van Zandwijk, ${ }^{10}$ Jukka Takala. ${ }^{1}$ Department of Environmental Epidemiology, Institute of Industrial Ecological Sciences, University of Occupational and Environmental Health, Kitakyushu, Japan; ${ }^{2}$ Asbestos Diseases Research Institute, Concord Clinical School, University of Sydney, Sydney, Australia; ${ }^{3}$ Institute of Applied Health Research, University of Birmingham, Birmingham, UK; ${ }^{4}$ School of Public Health, University of Sydney, Sydney, Australia; ${ }^{5}$ Department of Medicine, Division of Hematology, Institute for Health Metrics and Evaluation, Washington, USA; ${ }^{6}$ Department of Medicine, Faculty of Medicine, Khon Kaen University, Khon Kaen, Thailand; ${ }^{7} J a p a n$ Occupational Safety and Health Resource Center, Tokyo, Japan; ${ }^{8}$ Second Department of Surgery, University of Occupational and Environmental Health, Kitakyushu, Japan; ${ }^{9}$ Department of Health Policy and Management, Institute of Industrial Ecological Sciences, University of Occupational and Environmental Health, Kitakyushu, Japan; ${ }^{10}$ Workplace Safety and Health Institute, Ministry of Manpower, Singapore

\subsection{6/oemed-2018-ICOHabstracts.373}

Introduction Mesothelioma, one of the occupational cancer, is increasingly recognised as a global health issue and the assessment of its global burden is warranted.

Objectives To descriptively analyse national mortality data and to use reported and estimated data to calculate the global burden of mesothelioma deaths.

Methods For the study period of 1994 to 2014, we grouped 230 countries into 59 countries with quality mesothelioma mortality data suitable to be used for reference rates, 45 countries with poor quality data, and 126 countries with no data, based on the availability of data in the WHO Mortality Database. To estimate global deaths, we extrapolated the gender- and age-specific mortality rates of the countries with quality data to all other countries.

Results The global numbers and rates of mesothelioma deaths have increased over time. The 59 countries with quality data recorded 15011 mesothelioma deaths per year over the three most recent years with available data (equivalent to 9.9 deaths per million per year). From these reference data, we extrapolated the global mesothelioma deaths to be 38400 per year, based on extrapolations for asbestos use.

Conclusions Although the validity of our extrapolation method depends on the adequate identification of quality mesothelioma data and appropriate adjustment for other variables, our estimates can be updated, refined, and verified because they are based on commonly accessible data and are derived using a straightforward algorithm. Our estimates are within the range of previously reported values but higher than the most recently reported values.

\section{GENDER INEQUALITIES IN WORK ACCIDENTS AND OCCUPATIONAL MUSCULOSKELETAL DISORDERS: FINDINGS FROM THE 2013 BRAZILIAN NATIONAL HEALTH SURVEY}

Fernando Feijo, Clara Menegale, Fabrício Cardoso, Luís Henrique Santos, Matheus Lemos. Federal University Of Pelotas, Pelotas, Brazil

\subsection{6/oemed-2018-ICOHabstracts.374}

Introduction Considering the need to deepen the understanding of inequities in occupational health, this study aimed to describe the prevalence of work accidents and occupational musculoskeletal disorders (MSD) in the Brazilian population, analysing gender inequalities. 